\title{
The Role of Osteocytes in Inflammatory Bone Loss
}

\author{
Corinne E. Metzger ${ }^{1 *}$ and S. Anand Narayanan ${ }^{2}$ \\ ${ }^{1}$ Department of Health and Kinesiology, Texas A\&M University, College Station, TX, United States, ${ }^{2}$ Department of Medical \\ Physiology, Texas A\&M Health Science Center, Bryan, TX, United States
}

Osteoimmunology investigations to-date have demonstrated the significant interactions between bone surface cells, osteoclasts and osteoblasts, and immune cells. However, there is a paucity of knowledge on osteocytes, cells embedded in the bone matrix, and their role in inflammation and inflammatory bone loss. Osteocytes communicate through various mechanisms; directly via dendritic processes and through secretion of proteins that can influence the formation and activity of osteoblasts and osteoclasts. Some osteocyte proteins (e.g., interleukin-6 and RANKL) also have roles within the immune system. In the context of mechanical loading/unloading, the regulatory role of osteocytes is well understood. More recent data on osteocytes in various inflammatory models suggest they may also aid in orchestrating inflammation-induced changes in bone turnover. In inflammatory conditions, osteocytes express multiple pro-inflammatory

OPEN ACCESS

Edited by:

Giorgio Mori,

University of Foggia, Italy

Reviewed by:

David M. Findlay,

University of Adelaide, Australia Nicole Horwood,

University of Oxford, United Kingdom

*Correspondence:

Corinne E. Metzger

metzgercorinne@gmail.com

Specialty section:

This article was submitted to

Bone Research,

a section of the journal

Frontiers in Endocrinology

Received: 17 December 2018

Accepted: 18 April 2019

Published: 14 May 2019

Citation:

Metzger CE and Narayanan SA (2019) The Role of Osteocytes in Inflammatory Bone Loss.

Front. Endocrinol. 10:285.

doi: 10.3389/fendo.2019.00285 cytokines which are associated with increases in bone resorption and declines in bone formation. Cytokines are known to also influence cell population growth, maturation, and responsiveness via various signaling modalities, but how they influence osteocytes has not been greatly explored. Furthermore, osteocytes may play regulatory roles in orchestrating bone's response to immunological changes in inflammatory conditions. This review will address what is known about osteocyte biology in physiological conditions and in response to varying immunological conditions, as well as highlight key areas of interest for future investigations.

Keywords: osteocyte, cytokines, inflammation, tumor necorosis factor (TNF), sclerostin

Bone continually adapts to its internal and external environment, undergoing formation and resorption to maintain bone mass. Bone loss is an imbalance of bone formation and resorption which occurs in many conditions including disuse, aging, and chronic inflammatory conditions such as inflammatory bowel disease (1), rheumatoid arthritis (2), psoriasis (3), and systemic lupus erythematosus (4). While comparatively less studied to disuse or age-related bone loss, inflammatory conditions are also associated with increased fracture incidence (4-8). Multiple other conditions with known inflammatory components are also associated with bone loss and increased bone fragility including type 2 diabetes (9), chronic kidney disease (10), spinal cord injury (11), and aging-related osteoporosis (12). While the role of immune factors and inflammation on various bone cells (osteoblasts, osteoclasts, stromal cells, marrow immune cells, bone precursor cells) have been extensively researched (13), the osteocyte response to inflammatory stimuli has been comparably less investigated. However, osteocytes have increasingly become appreciated as key regulators of both osteoclasts and osteoblasts, orchestrating changes in bone turnover. 


\section{INTERACTIONS OF THE IMMUNE SYSTEM AND BONE}

The immune system interacting with bone physiology is being elucidated in the burgeoning field of osteoimmunology. For example, cytokines are signaling proteins released by various cell-types that modulate the direction of an immune response but can also influence the cellular phenotype of immune and parenchymal cells. In general, pro-inflammatory cytokines are grouped as $\mathrm{Th}_{1}$, while anti-inflammatory cytokines as $\mathrm{Th}_{2}$ (14). Notably, cytokines can interact with bone cells leading to increased bone resorption and decreased bone formation that, over time, leads to inflammatory bone loss (15). Key $\mathrm{Th}_{1}$ cytokines include TNF- $\alpha$ and IL- $1 \beta$, both stimulators of osteoclastogenesis (16-19). Additionally, these cytokines increase the production of RANKL, a key osteoclastogenesis regulator (20-22). TNF- $\alpha$ can also increase production of OPG, the decoy receptor for RANKL (23). IL-6 has equivocal roles in bone physiology, but, with TNF- $\alpha$, IL- 6 synergizes to stimulate osteoclasts and increase production of RANKL and OPG (21). IL-17 is also a potent stimulus for osteoclastogenesis (24) and sensitizes osteoclast pre-cursors to RANKL (25).

In addition to stimulating an increase in osteoclasts and bone resorption, $\mathrm{Th}_{1}$ cytokines interact with osteoblast development and function. For example, TNF- $\alpha$ inhibits osteoblast genes and differentiation factors (e.g., RUNX2), and reduces bone collagen synthesis (20, 26-28). TNF- $\alpha$ also inhibits the anabolic effects of IGF-I on osteoblasts (29) and induces osteoblast apoptosis $(20,30)$. Interleukin-1 $\beta$ (IL-1 $\beta$ ) has been shown to also suppress bone formation (31). In addition to osteoblasts and osteoclasts, other cell types residing in the bone environment such as bone marrow stromal cells and osteoblast/osteoclast-precursor cells can be influenced in their function by cytokines $(32,33)$. This illustrates the critical role of immunological factors, such as $\mathrm{Th}_{1}$ cytokines, in bone biology.

$\mathrm{Th}_{2}$ cytokines, such as IL-4 and IL-10, are less well understood in the context of bone physiology. In cell culture models, both IL4 and IL-10 have been shown to inhibit osteoclasts and reduce RANKL production (34-37). Another cell culture study found both IL-4 and IL-13 increased OPG mRNA expression; thus, decreasing RANKL mediated osteoclastogenesis in vitro (38). Furthermore, IL-10 transgenic knockout mice have low bone mass and increased fragility which alludes to an influential role of IL-10 in regulating bone turnover (39). There exist many other cytokines within the $\mathrm{Th}_{1}$ and $\mathrm{Th}_{2}$ classes and other subsets $\left(\mathrm{Th}_{9}, \mathrm{Th}_{17}, \mathrm{Th}_{22}, \mathrm{~T}_{\mathrm{fh}}\right)$ that have roles not yet delineated in bone physiology, highlighting areas of future research. Finally, the interaction of these cytokines with osteocytes has been minimally investigated.

\section{OSTEOCYTE BIOLOGY}

Osteocytes are the longest living bone cell, making up 90-95\% of cells in bone tissue in contrast to osteoclasts and osteoblasts making up $5 \%$ (40). Osteocytes form when osteoblasts become buried in the mineral matrix of bone and develop distinct features. Residing within the lacuna of the mineralized bone matrix, osteocytes form dendritic processes that extend out from their cell bodies into spaces known as canaliculi. Through these dendritic processes, osteocytes form networks interfacing with other osteocytes, cells on bone surfaces, and the marrow (40). Through these communication networks, osteocytes sense the local and systemic environment within the bone.

Osteocytes also coordinate the actions of osteoblasts and osteoclasts via several mechanisms. First, osteocytes express and release proteins that signal to osteoblasts, osteoclasts, and other bone-residing cells to respond to environmental changes. Osteocytes express important factors for the maintenance of mineral homeostasis including SOST, Phex, DMP1, and FGF23 (41). Sclerostin, the protein encoded by the SOST gene, is an antagonist of the $\mathrm{Wnt} / \beta$-catenin system, with increased sclerostin expression leading to a suppression of bone formation (42-44). Osteocytes also produce RANKL and OPG, critical regulators of osteoclastogenesis. While osteoblasts and other bone-residing immune cells also produce RANKL, it is now appreciated that RANKL synthesized by osteocytes is a significant source of RANKL driving osteoclast formation for bone remodeling (45-47). Additionally, osteocyte apoptosis signals to increase osteoclast activity driving targeted bone resorption $(41,48,49)$. Elucidating osteocyte function in the context of osteoimmunology may provide further insight to the imbalance of resorption vs. formation seen in inflammationinduced bone loss.

\section{THE ROLE OF OSTEOCYTES IN ADAPTATIONS TO MECHANICAL STRAINS}

In the past few decades, the central role of osteocytes in response to mechanical strains has been explored and identified. Osteocytes sense mechanical strains through fluid flow shear stress through the lacuna-canalicular network and changes in interstitial hydrostatic pressure (50-52). Decreased mechanical strains also induce osteocyte apoptosis leading to decreased bone mass and strength $(53,54)$. Some preliminary evidence suggests that high mobility group box 1 (HMGB1), an alarmin (55), may be released during osteocyte apoptosis thereby triggering RANKL and other immune factors (56). It is unknown what other immune-related factors may be released during apoptosis and the signaling cascades that follow.

Mechanosensory signals also trigger osteocytes to release various proteins that impact bone turnover. RANKL and OPG are also known to be mechanosensitive (57) and mice lacking osteocyte RANKL are protected from disuse-induced bone loss (46). Furthermore, unloading-induced osteocyte apoptosis initiates an increase in osteocyte RANKL (54). Prevention of osteocyte apoptosis in animal models of unloading mitigates increases in osteocyte RANKL $(54,58)$. Disuse is also characterized by elevated osteocyte sclerostin in conjunction with decreased bone formation rate $(59,60)$. Other mechanosensitive osteocyte proteins include insulin-like growth factor-I (IGFI) and IL-6 which both are upregulated with loading (6063). The role of osteocytes in the mechanosensory capabilities 
of bone highlight the important role these cells play in bone adaptations to the environment. Some osteocyte proteins known to have mechanosensory roles such as RANKL and IL-6 are also signaling molecules in the immune system and play key roles in inflammatory processes. This suggests that other cytokines may perhaps have similar dual roles responding under conditions of loading/unloading and under conditions of inflammation.

\section{OSTEOCYTES AND CYTOKINES}

Burgeoning research has shown cytokines directly impact osteocyte apoptosis and cause the release of cytokines that influence bone turnover. In cell culture models, osteocyte apoptosis can be induced by both TNF- $\alpha$ and IL-1 (64-66). A mouse infectious osteomyelitis model lead to increases in osteocyte apoptosis, as well as elevations in gene expression of TNF- $\alpha$, IL-1 $\beta$, IL- 6 , and IL- 17 in the femur; the same treatment in TNF- $\alpha$ deficient mice resulted in fewer apoptotic osteocytes (67). We previously demonstrated in rats with inflammatory bowel disease decreased osteocyte density and increased apoptosis concurrent with elevated osteocyte TNF- $\alpha(68,69)$. Therefore, one mechanism of increased bone resorption in inflammatory conditions is through the direct effect of pro-inflammatory cytokines on osteocyte apoptosis which, in turn, increases osteoclastic driven resorption.

Osteocytes also express pro-inflammatory cytokines. TNF- $\alpha$ is expressed in the MLO-Y4 osteocyte-like cell culture line $(70,71)$, as is IL-6 (61). Cultured human trabecular bone chips expressing osteocyte-specific genes also express TNF- $\alpha$, IL-6, IL-1 $\beta$, and IL-8 (72). Other cell culture osteocyte lines have increased expression of pro-inflammatory cytokines with exposure to monosodium urate crystals (73), Brucella abortus infection (74) and orthopedic implant materials (75). Immunohistochemical analysis of rat bones demonstrate elevated osteocyte TNF- $\alpha$, IL-6, and IL17 in various inflammatory conditions $(68,69,76)$. Therefore, osteocytes express cytokines that can increase osteoclastogenesis and inhibit osteoblast formation or activity.

Osteocytes themselves respond to circulating proinflammatory cytokines influencing their cytokine expression. For example, exposing MLO-Y4 osteocytes in culture to IL-17 increases expression of TNF- $\alpha$ (71). In cultured human bone chips with osteocyte-enriched cells, gene expression of TNF- $\alpha$, IL- $1 \beta$, and IL- 6 is elevated upon treatment combinations of TNF- $\alpha$, IL-1 $\beta$, and IL-6 (72). Based on the supporting data from these in vitro studies, cytokines influence osteocytes in a positive-feedback mechanism leading to even greater cytokine expression. This would suggest osteocytes may amplify an inflammatory bone state resulting in increased production of factors altering bone turnover and increasing bone loss.

Many cytokines also alter osteocyte signaling proteins. Osteocyte-to-osteoclast signaling is enhanced by multiple proinflammatory cytokines largely through RANKL signaling. Culture media from IL-1 $\beta$-treated MLO-Y4 cells increased osteoclastogenesis in vitro (77). Furthermore, blocking IL-17A prevented the increase in osteocyte RANKL due to continuous parathyroid hormone exposure (78).

MLO-Y4 cells treated with IL-6/IL-6R and co-cultured with osteoclast precursors also results in increased osteoclastogenesis due to elevated RANKL (79). Furthermore, RANKL-positive osteocytes are elevated in animal models of inflammatory conditions including periodontitis (80-82), spinal cord injury (76), and inflammatory bowel disease $(68,69)$. Furthermore, in rat models of inflammatory bowel disease and spinal cord injury, RANKL-positive osteocytes were associated with increases in osteoclast surfaces $(68,76)$. In contrast to RANKL, OPG is less well understood in conditions of inflammation. Treatment of cultured human osteocytes- with a combination of IL-1 $\beta$, TNF$\alpha$, and IL-6 upregulates OPG (72). In rodent inflammatory bowel disease and spinal cord injury models, OPG-positive osteocytes were elevated $(68,69,76)$. Therefore, while the exact role of OPG is not known, it is known that inflammatory cytokines regulate osteoclastogenesis in part through osteocyte-mediated RANKL/OPG signaling.

Inflammatory signals also influence osteocyte proteins controlling bone formation. Wnt proteins are key mediators of osteoblastogenesis and govern the formation of the skeletal development. Both sclerostin and Dickkopf-related-1 (Dkk-1) inhibit the Wnt signaling pathway in bone. Dkk-1 is upregulated by TNF- $\alpha$ and blockade against Dkk- 1 in transgenic mice with inflammatory arthritis prevents bone loss (83); however, osteocyte-specific deletion of Dkk1 did not protect against inflammatory arthritis-induced bone loss (84). Interestingly, Dkk1 expression was inhibited in osteoblast cell culture treated with IL-17A; whether this is also true in osteocytes is unknown (85). Sclerostin has also been shown to bind to LRP5/6 and inhibit Wnt signaling in vitro and in vivo $(42,86)$, and be transcriptionally activated by TNF- $\alpha$ (87). In human osteocyteenriched cell cultures, serum from rheumatoid arthritis patients, IL- $1 \beta$ alone, and a combination of IL- $1 \beta$, TNF- $\alpha$, and IL- 6 all increased SOST expression (72). Furthermore, osteocyte sclerostin is elevated in animal models of high fat diets with elevated serum and osteocyte TNF- $\alpha$ (87), inflammatory arthritis (83), periodontitis alveolar bone $(81,82)$, spinal cord injury (76), and inflammatory bowel disease $(68,69)$. Beyond direct effects of pro-inflammatory cytokines on osteoblasts and bone formation, the inflammation-induced elevation of inhibitors of bone formation contributes to a state of low bone formation.

While outside the scope of this review, additional osteocyte proteins involved in mineral homeostasis and metabolism are influenced by inflammatory signals. Fibroblast growth factor 23 (FGF23), a phosphate regulator synthesized by osteocytes, has increased expression in inflammatory conditions $(72,88,89)$. IL-17A has been shown to decrease various genes of osteocyte proteins involved in mineral metabolism including Dmp1 and Phex (90). Therefore, it is clear that osteocytes respond to inflammatory signals through various mechanisms including increased expression of cytokines and altered expression of regulatory proteins. 


\section{MECHANOSENSING AND INFLAMMATORY SIGNALS}

Crucial to osteocyte function is sensing and responding to bone interstitial fluid shear stress and mechanical strains. Furthermore, there is some overlap in signaling proteins between inflammation and mechanosensing (sclerostin, RANKL, OPG, etc.). What is not fully understood is if mechanosensing is tied with osteocyte inflammatory responses and vice versa. Utilizing pulsatile fluid flow in MLO-Y4 cells, TNF- $\alpha$, and IL- $1 \beta$ treatment inhibits fluid flow-induced increases in calcium uptake and nitric oxide release indicating a potential blunting of the osteocyte response to mechanical strains (65). Another investigation found media from MLO-Y4 cells cultured with IL-1 $\beta$ induced osteoclastogenesis, while IL-1 $\beta$-cultured cells that also underwent pulsatile fluid flow prevented osteoclastogenesis (77). Pulsatile fluid flow reduced MLO-Y4 expression of TNF- $\alpha$ - and IL-17A-induced increases in TNF- $\alpha$ and RANKL (71), inhibited TNF- $\alpha$-induced osteocyte apoptosis (66), and increased IL-6 production in osteocyte cultured cells (61).

With aging, osteocytes develop morphological adaptations and changes in the lacunocanalicular system that may impair their mechanosensory function and ability to communicate $(91,92)$. In addition, osteocytes of aged mice also express a senescence-associated secretory-phenotype, expressing multiple pro-inflammatory cytokines including IL-17A, IL-1A, and IL-6, likely contributing to age-related bone loss (93). Prevention of the pro-inflammatory secretome of senescent cells in aged mice with a JAK inhibitor improved bone mass and strength (94). It has been hypothesized that exercise to increase mechanical strain on bone could improve the senescent phenotype in aging (95). It remains to been seen whether a lack of mechanical loading and a lack of adequate mechanosensory ability or pro-inflammatory senescent markers occurs first during aging in osteocytes.

To our knowledge, there are no investigations directly assessing the influence of mechanical loading on osteocyterelated proteins in animal models of inflammatory conditions to determine the mechanical loading effects on osteocyte inflammatory changes. However, it is possible that in inflammatory pathologies, such as spinal cord injury where both chronic systemic inflammation and disuse are present, the inflammatory status with the lack of mechanical loading on osteocytes could exacerbate bone loss. Further work needs to be done on the interaction of inflammation and mechanical strains in osteocytes.

\section{FUTURE DIRECTIONS}

With the accumulating knowledge of the role of osteocytes in inflammatory bone loss, future areas of interest may include

\section{REFERENCES}

1. Agrawal M, Arora S, Li J, Rahmani R, Sun L, Steinlauf AF, et al. Bone, inflammation, and inflammatory bowel disease. Curr Osteoporos Rep. (2011) 2011:251-7. doi: 10.1007/s11914-011-0 077-9 therapeutically targeting osteocytes in inflammatory bone loss conditions. In inflammatory conditions, bone-specific treatments like bisphosphonates, anti-RANKL, and anti-sclerostin, all improve bone outcomes, but have no effect on inflammatory measures (96-98). Anti-inflammatory treatments, like antiTNF, may improve bone mass (99), but potentially have negative side effects $(100,101)$. Therefore, viable treatments for inflammatory conditions are still needed. By directly impacting osteocytes via senolytic treatment or a JAK inhibitor in aged mice prevented the inflammatory senescent osteocyte phenotype (94). Additionally, in rodent models of inflammatory bowel disease, a soy protein diet and treatment with exogenous irisin decreased the inflammatory status of osteocytes and improved bone turnover $(69,102)$. Other anti-inflammatory treatments that improve bone in inflammatory conditions, like resolvin E1 (103), need to be examined for their impact on osteocytes. Furthermore, low-grade inflammation may be beneficial in some conditions like fracture healing (104). The role of other cytokines in bone physiology still needs to be elucidated as well as the relative contribution of osteocytic proinflammatory cytokines vs. those from other cell types in the marrow. Finally, the magnitude and duration of mechanical forces that could influence osteocyte-immune crosstalk has yet to be examined.

\section{CONCLUSIONS}

Osteocytes play a central role in orchestrating changes in bone turnover. In this review, we present literature that supports an overlap between classical osteocyte regulatory proteins with known mechanosensory functions (RANKL, OPG, sclerostin, etc.) and immune factors that directly impact osteocytes and their communication with osteoblasts and osteoclasts. Pro-inflammatory signals stimulate osteocyte apoptosis, increase osteocyte cytokine production, and alter osteocytic proteins controlling bone turnover. Therefore, osteocytes are key players in inflammatory bone loss. This indicates that osteocytes may be targets for preventing/treating inflammatory bone alterations.

\section{AUTHOR CONTRIBUTIONS}

$\mathrm{CM}$ and $\mathrm{SN}$ drafted and edited the manuscript and approved the final version.

\section{ACKNOWLEDGMENTS}

The authors would like to thank Dr. Susan A. Bloomfield for her support.
2. Attia EAS, Khafagy A, Abdel-Raheem S, Fathi S, Saad AA. Assessment of osteoporosis in psoriasis with and without arthritis: correlation with disease severity. Int J Dermatol. (2011) 50:30-5. doi: 10.1111/j.1365-4632.2010.04600.x

3. Haugeberg G, Uhlig T, Falch JA, Halse JI, Kvien TK. Bone mineral density and frequency of osteoporosis in female patients 
with rheumatoid arthritis. Arthritis Rheum. (2000) 43:522-30. doi: 10.1002/1529-0131(200003)43:3<522::AID-ANR7 > 3.0.CO;2-Y

4. Bultink IEM. Osteoporosis and fractures in systemic lupus erthyematosus. Arthritis Care Res. (2012) 64:2-8. doi: 10.1002/acr.20568

5. Bernstein CM, Blanchard JF, Leslie W, Wadja A, Yu BN. Incidence of fracture among patients with inflammatory bowel disease. Ann Intern Med. (2000) 133:795-9. doi: 10.7326/0003-4819-133-10-200011210-00012

6. Klaus J, Armbrecht G, Steinkamp M, Brückel J, Rieber A, Adler G, et al. High prevalence of osteoporotic vertebral fractures in patients with Crohn's disease. Gut. (2002) 51:654-8. doi: 10.1136/gut.51.5.654

7. Van Staa TP, Geusens P, Bijlsma JWJ, Leufkens HGM, Cooper C. Clinical assessment of the long-term risk of fracture in patients with rheumatoid arthritis. Arthritis Rheum. (2006) 54:3104-12. doi: 10.1002/art.22117

8. Ogdie A, Harter L, Shin D, Baker J, Takeshita J, Choi HK, et al. The risk of fracture among patients with psoriatic arthritis and psoriasis: a population-based study. Ann Rheum Dis. (2017) 76:882-5. doi: 10.1136/annrheumdis-2016-210441

9. Donath MY, Shoelson SE. Type 2 diabetes as an inflammatory disease. Nature Rev Immunol. (2011) 11:98-107. doi: 10.1038/nri2925

10. Miyamoto T, Carrero JJ, Stenvinkel P. Inflammation as a risk factor and target for therapy in chronic kidney disease. Curr Opinion Nephrol Hypertens. (2011) 20:662-8. doi: 10.1097/MNH.0b013e32834ad504

11. Allison DJ, Ditor DS. Immune dysfunction and chronic inflammation following spinal cord injury. Spinal Cord. (2015) 53:14-8. doi: $10.1038 /$ sc.2014.184

12. Ginaldi L, Di Benedetto MC, De Martinis M. Osteoporosis, inflammation and ageing. Immun Ageing. (2005) 2:14. doi: 10.1186/1742-4933-2-14

13. Okamoto K, Nakashima T, Shinohara M, Negishi-Koga T, Komatsu $\mathrm{N}$, Terashima A, et al. Osteoimmunology: the conceptual framework unifying the immune and skeletal systems. Physiol Rev. (2017) 97:1295-349. doi: 10.1152/physrev.00036.2016

14. Turner MD, Nedjai B, Hurst T, Pennington DJ. Cytokines and chemokines: at the crossroads of cell signalling and inflammatory disease. BBA-Mol Cell Res. (2014) 1843:2563-82. doi: 10.1016/j.bbamcr.2014.05.014

15. Redlich K, Smolen JS. Inflammatory bone loss: pathogenesis and therapeutic intervention. Nature Rev. (2012) 11:234-50. doi: 10.1038/nrd3669

16. Kobayashi K, Takahashi N, Jimi E, Udagawa N, Takami M, Kotake S, et al. Tumor necrosis factor- $\alpha$ stimulates osteoclast differentiation by a mechanism independent of the ODF/RANKL-RANK interaction. J Exp Med. (2000) 191:275-85. doi: 10.1084/jem.191.2.275

17. Lam J, Takeshita S, Barker JE, Kanagawa O, Ross FP, Teitelbaum SL. TNF$\alpha$ induces osteoclastogenesis by direct stimulation of macrophages exposed to permissive levels of RANK ligand. J Clin Invest. (2000) 106:1481-8. doi: 10.1172/JCI11176

18. Gowen M, Wood DD, Ihrie EJ, McGuire MKB, Russell GG. An interleukin 1 like factor stimulates bone resorption in vitro. Nature. (1983) 306:378-80. doi: $10.1038 / 306378 \mathrm{a} 0$

19. Pfeilschifter J, Chenu C, Bird A, Mundy GR, Roodman GD. Interleukin-1 and tumor necrosis factor stimulate the formation of human osteoclastlike cells in vitro. J Bone Miner Res. (1989) 4:113-8. doi: 10.1002/jbmr.5650040116

20. Nanes MS. Tumor necrosis factor- $\alpha$ : molecular and cellular mechanisms in skeletal pathology. Gene. (2003) 321:1-15. doi: 10.1016/S03781119(03)00841-2

21. Steeve KT, Marc P, Sandrine T, Dominique H, Yannick F. IL-6, RANKL, TNFalpha/IL-1: interrelations in bone resorption pathology. Cytokine Growth Factor Rev. (2004) 15:49-60. doi: 10.1016/j.cytogfr.2003.10.005

22. Hofbauer LC, Lacey DL, Dunstan CR, Spelsberg TC, Riggs BL, Khosla S. Interleukin- $1 \beta$ and tumor necrosis factor- $\alpha$, but not interleukin- 6 , stimulate osteoprotegerin ligand gene expression in human osteoblastic cells. Bone. (1999) 25:255-9. doi: 10.1016/S8756-3282(99)00162-3

23. Hofbauer LC, Dunstan CR, Spelsberg TC, Riggs BL, Khosla S. Osteoprotegerin production by human osteoblast lineage cells is stimulated by vitamin $\mathrm{D}$, bone morphogenetic protein-2, and cytokines. Biochem Biophys Res Comm. (1998) 250:776-81. doi: 10.1006/bbrc.1998.9394

24. Kotake S, Udagawa N, Takahashi N, Matsuzaki K, Itoh K, Ishiyama S, et al. IL-17 in synovial fluids from patients with rheumatoid arthritis is a potent stimulator of osteoclastogenesis. J Clin Invest. (1999) 103:1345-52. doi: 10.1172/JCI5703

25. Adamopoulos IE, Chao C, Geissler R, Laface D, Blumenschein W, Iwakura $Y$, et al. Interleukin-17A upregulates receptor activator of NF- $\mathrm{kB}$ on osteoclast precursors. Arthr Res Ther. (2010) 12:R29. doi: 10.1186/ar2936

26. Abbas S, Zhang YH, Clohisy JC, Abu-Amer Y. Tumor necrosis factor- $\alpha$ inhibits pre-osteoblast differentiation through its type-1 receptor. Cytokine. (2003) 22:33-41. doi: 10.1016/S1043-4666(03)00106-6

27. Bertolini DR, Nedwin GE, Bringman TS, Smith DD, Mundy GR. Stimulation of bone resorption and inhibition of bone formation in vitro by human tumor necrosis factors. Nature. (1986) 319:516-8. doi: 10.1038/319 $516 \mathrm{a} 0$

28. Kaneki H, Guo R, Chen D, Yao Z, Schwarz EM, Zhang YE, et al. Tumor necrosis factor promotes Runx2 degradation through up-regulation of Smurf1 and Smurf2 in osteoblasts. J Biol Chem. (2006) 281:4326-33. doi: 10.1074/jbc.M509430200

29. Scharla SH, Strong DD, Mohan S, Chevalley T, Linkhart TA. Effect of tumor necrosis factor- $\alpha$ on the expression of insulin-like growth factor I and insulin-like growth factor binding protein 4 in mouse osteoblasts. Eur J Endocrinol. (1994) 131:293-301. doi: 10.1530/eje.0.1310293

30. Pavalko FM, Gerard RL, Ponik SM, Gallagher PJ, Jin Y, Norvell SM. Fluid shear stress inhibits TNF-a-induced apoptosis in osteoblasts: A role for fluid shear stress-induced activation of PI3-kinase and inhibition of caspase-3. $J$ Cell Physiol. (2002) 194:194-205. doi: 10.1002/jcp.10221

31. Stashenko P, Dewhirst FE, Rooney ML, Desjardins LA, Heeley JD. Interleukin- $1 \beta$ is a potent inhibitor of bone formation in vitro. J Bone Miner Res. (1987) 2:559-65. doi: 10.1002/jbmr.5650020612

32. Bernardo ME, Fibbe WE. Mesenchymal stromal cells: sensors and switchers of inflammation. Cell Stem Cell. (2013) 13:392-402. doi: 10.1016/j.stem.2013.09.006

33. Crotti TN, Dharmapatni AA, Alias E, Haynes DR. Osteoimmunology: major and costimulatory pathway expression associated with chronic inflammatory induced bone loss. J Immunol Res. (2015) 2015:281287. doi: $10.1155 / 2015 / 281287$

34. Cheng J, Liu J, Shi Z, Xu D, Luo S, Siegal GP, et al. Interleukin-4 inhibits RANKL-induced NFATc1 expression via STAT6: A novel mechanism mediating its blockade of osteoclastogenesis. J Cell Biochem. (2011) 112:3385-92. doi: $10.1002 /$ jcb. 23269

35. Evans KE, Fox SW. Interleukin-10 inhibits osteoclastogenesis by reducting NFATc1 expression and preventing its translocation to the nucleus. BMC Cell Biol. (2007) 8:4. doi: 10.1186/1471-2121-8-4

36. Fujii T, Kitaura H, Kimura K, Hakami ZW, Takano-Yamamoto T. IL4 inhibits TNF- $\alpha$-mediated osteoclast formation by inhibition of RANKL expression in TNF- $\alpha$-activated stromal cells and direct inhibition of TNF- $\alpha$ activated osteoclast precursors via a T-cell-independent mechanism in vivo. Bone. (2012) 51:771-80. doi: 10.1016/j.bone.2012.06.024

37. Xu LX, Kukita $\mathrm{T}$, Kukita $\mathrm{A}$, Otsuka $\mathrm{T}$, Niho $\mathrm{Y}$, Iijima $\mathrm{T}$. Interleukin10 selectively inhibits osteoclastogenesis by inhibiting differentiation of osteoclast progenitors into preosteoclast-like cells in rat bone marrow culture system. Cell Physiol. (1995) 165:624-9. doi: 10.1002/jcp.1041650321

38. Stein NC, Kreutzmann C, Zimmermann SP, Niebergall U, Hellmeyer L, Goettsch C, et al. Interleukin-4 and interleukin-13 stimulate the csteoclast inhibitor osteoprotegerin by human endothelial cells through the STAT6 pathway. J Bone Miner Res. (2008) 23:750-8. doi: 10.1359/jbmr.080203

39. Dresner-Pollak R, Gelb N, Rachmilewitz D, Karmeli F, Weinreb M. Interleukin 10-deficient mice develop osteopenia, decreased bone formation, and mechanical fragility of long bones. Gastroenterol. (2004) 127:792-801. doi: $10.1053 /$ j.gastro.2004.06.013

40. Bonewald LF. Osteocytes as dynamic multifunctional cells. Ann NY Acad Sci. (2007) 1116:281-90. doi: 10.1196/annals.1402.018

41. Bonewald LF. The amazing osteocyte. J Bone Miner Res. (2011) 26:229-38. doi: $10.1002 / j b m r .320$

42. Li X, Zhang Y, Kang H, Liu W, Liu P, Zhang J, et al. Sclerostin binds to LRP5/6 and antagonizes canonical Wnt signaling. J Biol Chem. (2005) 280:19883-7. doi: 10.1074/jbc.M413274200

43. Ten Dijke P, Krause C, de tGorter DJJ, Lowick CWGM, van Bezooijen RL. Osteocyte-derived sclerostin inhibits bone formation: its role in bone 
morphogenetic protein and Wnt signaling. J Bone Joint Surg. (2008) 90:31-5. doi: 10.2106/JBJS.G.01183

44. Winkler DG, Sutherland MK, Geoghegan JC, Yu C, Hayes T, Skonier JE, et al. Osteocyte control of bone formation via sclerostin, a novel BMP antagonist. EMBO J. (2003) 22:6267-76. doi: 10.1093/emboj/cdg599

45. Nakashima T, Hayashi M, Fukunaga T, Kurata K, Oh-hora M, Feng JQ, et al. Evidence for osteocyte regulation of bone homeostasis through RANKL expression. Nat Med. (2011) 17:1231-4. doi: 10.1038/nm.2452

46. Xiong J, Onal M, Jilka RL, Weinstein RS, Manolagas SC, O’Brien CA. Matrix-embedded cells control osteoclast formation. Nature Med. (2011) 17:1235-42. doi: $10.1038 / \mathrm{nm} .2448$

47. Xiong J, Piemontese M, Onal M, Campbell J, Goellner JJ, Dusevich V, et al. Osteocytes, not osteoblasts or lining cells, are the main source of the RANKL required for osteoclast formation in remodeling bone. PLoS ONE. (2015) 10:e0138189. doi: 10.1371/journal.pone.0138189

48. Manolagas SC, Parfitt AM. For whom the bell tolls: Distress signals from long-lived osteocytes and the pathogenesis of metabolic bone disease. Bone. (2013) 54:272-82. doi: 10.1016/j.bone.2012.09.017

49. Plotkin LI. Apoptotic osteocytes and the control of targeted bone resorption. Curr Osteoporos Rep. (2014) 12:121-6. doi: 10.1007/s11914-014-0194-3

50. Bonewald LF, Johnson ML. Osteocytes, mechanosensing and Wnt signaling. Bone. (2008) 42:606-15. doi: 10.1016/j.bone.2007.12.224

51. Burger EH, Klein-Nulend J. Mechanotransduction in bone - role of the lacunocanalicular network. FASEB J. (1999) 13:S101-S112. doi: 10.1096/fasebj.13.9001.s101

52. Schaffler MB, Cheung WY, Majeska R, Kennedy O. Osteocytes: Master orchestrators of bone. Calcif Tissue Int. (2014) 94:5-24. doi: 10.1007/s00223-013-9790-y

53. Aguirre JI, Plotkin LI, Stewart SA, Weinstein RS, Parfitt AM, Manolagas SC, et al. Osteocyte apoptosis is induced by weightlessness in mice and precedes osteoclast recruitment and bone loss. J Bone Miner Res. (2006) 21:605-15. doi: 10.1359/jbmr.060107

54. Cabahug-Zuckerman P, Frikha-Benayed D, Majeska RJ, Tuthill A, Yakar S, Judex S, et al. Osteocyte apoptosis caused by hindlimb unloading is required to trigger osteocyte RANKL production and subsequent resorption of cortical and trabecular bone in mice femurs. J Bone Miner Res. (2016) 31:1356-65. doi: 10.1002/jbmr.2807

55. Nefla M, Holzinger D, Berenbaum F, Jacques C. The danger from within: alarmins in arthritis. Nature Rev Rheumatol. (2016) 12:669. doi: 10.1038/nrrheum.2016.162

56. Bidwell JP, Yang J, Robling AG. Is HMGB1 an osteocyte alarmin? J Cell Biochem. (2008) 103:1671-80. doi: 10.1002/jcb.21572

57. You L, Temiyasathit S, Lee P, Kim CH, Tummala P, Yao W, et al. Osteocytes as mechanosensors in the inhibition of bone resorption due to mechanical loading. Bone. (2008) 42:172-9. doi: 10.1016/j.bone.2007.09.047

58. Plotkin LI, Gortazar AR, Davis HM, Condon KW, Gabilondo H, Maycas M, et al. Inhibition of osteocyte apoptosis prevents the increase in osteocytic receptor activator of nuclear factor $\kappa \mathrm{B}$ ligand (RANKL) but does not stop bone resorption or the loss of bone induced by unloading. J Biol Chem. (2015) 290:18934-42. doi: 10.1074/jbc.M115.642090

59. Robling AG, Niziolek PJ, Baldridge LA, Condon KW, Allen MR, Alam I, et al. Mechanical stimulation of bone in vivo reduces osteocyte expression of Sost/sclerostin. J Biol Chem. (2008) 283:5866-75. doi: 10.1074/jbc.M705092200

60. Metzger CE, Brezicha JE, Elizondo JP, Narayanan SA, Hogan HA, Bloomfield SA. Differential responses of mechanosensitive osteocyte proteins in fore- and hindlimbs of hindlimb-unloaded rats. Bone. (2017) 105:26-34. doi: 10.1016/j.bone.2017.08.002

61. Bakker AD, Kulkarni RN, Klein-Nulend J, Lems WF. IL-6 alters osteocyte signaling toward osteoblasts but not osteoclasts. J Dent Res. (2014) 93:394-9. doi: $10.1177 / 0022034514522485$

62. Lau KHW, Baylink DJ, Zhou XD, Rodriguez D, Bonewald LF, Li Z, et al. Osteocyte-derived insulin-like growth factor I is essential for determining bone mechanosensitivity. Am J Physiol Endocrinol Metab. (2013) 305:E27181. doi: 10.1152/ajpendo.00092.2013

63. Reijnders CMA, Bravenboer N, Tromp AM, Blankenstein MA, Lips P. Effect of mechanical loading on insulin-like growth factor-I gene expression in rat tibia. J Endocrinol. (2007) 192:131-40. doi: 10.1677/joe.1.06880
64. Ahuja SS, Zhao S, Bellido T, Plotkin LI, Jimenez F, Bonewald LF. CD40 ligand blocks apoptosis induced by tumor necrosis factor- $\alpha$, glucocorticoids, and etoposide in osteoblasts and the osteocyte-like cell line murine long bone osteocyte-Y4. Endocrinol. (2003) 144:1761-9. doi: 10.1210/en.2002-221136

65. Bakker AD, da Silva VC, Krishan R, Bacabac RG, Blaauboer ME, Lin YC, et al. Tumor necrosis factor- $\alpha$ and interleukin- $1 \beta$ modulate calcium and nitric oxide signaling in mechanically stimulated osteocytes. Arthritis Rheum. (2009) 60:3336-45. doi: 10.1002/art.24920

66. Tan SD, Kuijpers-Jagtman AM, Semeins CM, Bronckers ALJJ, Maltha JC, Von den Hoff JW, et al. Fluid shear stress inhibits TNF- $\alpha$ induced osteocyte apoptosis. J Dent Res. (2006) 85:2006. doi: 10.1177/154405910 608501006

67. Morita M, Iwasaki R, Sato Y, Kobayashi T, Watanabe R, Oike T, et al. Elevation of pro-inflammatory cytokine levels following anti-resorptive drug treatment is required for osteonecrosis development in infectious osteomyelitis. Sci Rep. (2017) 7:46322. doi: 10.1038/srep46322

68. Metzger CE, Narayanan A, Zawieja DC, Bloomfield SA. Inflammatory bowel disease in a rodent model alters osteocyte protein levels controlling bone turnover. J Bone Miner Res. (2017b) 32:802-13. doi: 10.1002/jbmr.3027

69. Narayanan SA, Metzger CE, Bloomfield SA, Zawieja DC. Inflammationinduced lymphatic architecture and bone turnover changes are ameliorated by irisin treatment in chronic inflammatory bowel disease. FASEB J. (2018) 32:4848-61. doi: 10.1096/fj.201800178R.

70. Kanaji A, Caicedo MS, Virdi AS, Sumner DR, Hallab NJ, Sena K. Co-Cr-Mo alloy particles induce tumor necrosis factor alpha production in MLO-Y4 osteocytes: A role for osteocytes in particle-induced inflammation. Bone. (2009) 45:528-33. doi: 10.1016/j.bone.2009.05.020

71. Liao C, Cheng T, Wang S, Zhang C, Jin L, Yang Y. Shear stress inhibits IL$17 \mathrm{~A}-$ mediated induction of osteoclastogenesis via osteocyte pathways. Bone. (2017) 101:10-20. doi: 10.1016/j.bone.2017.04.003

72. Pathak JL, Bakker AD, Luten FP, Verschueren P, Lems WF, KleinNulend J, et al. Systemic inflammation affects human osteocyte-specific protein and cytokine expression. Calcif Tissue Int. (2016) 98:596-608. doi: 10.1007/s00223-016-0116-8

73. Chhana A, Pool B, Callon KE, Tay ML, Musson D, Naot D, et al. Monosodium urate crystals reduce osteocyte viability and indirectly promote a shift in osteocyte function towards a proinflammatory and proresorptive state. Arthritis Res Ther. (2018) 20:208. doi: 10.1186/s13075-018-1704-y

74. Viglietti AIP, Benitez PCA, Gentilini MB, Velásquez LN, Fossati CA, Giambartolomei GH, et al. Brucella abortus invasion of osteocytes modulates connexin 43 and integrin expression and induces osteoclastogenesis via receptor activator of NF-kB ligand and tumor necrosis factor-alpha secretion. Infect Immun. (2015) 84:11-20. doi: 10.1128/IAI.01049-15

75. Ormsby RT, Solomon LB, Yang D, Crotti TN, Haynes DR, Findlay DM, et al. Osteocytes respond to particles of clinically-relevant conventional and cross-linked polyethylene and metal alloys by up-regulation of resorptive and inflammatory pathways. Acta Biomater. (2019) 87:296-306. doi: 10.1016/j.actbio.2019.01.047

76. Metzger CE, Narayanan SA, Zawieja DC, Bloomfield SM. A moderately elevated soy protein diet mitigates inflammatory changes in gut and in bone turnover during chronic TNBS-induced inflammatory bowel disease. Appl Physiol Nutr Met. (2018) 2018:23. doi: 10.1139/apnm-2018-0514

77. Kulkarni RN, Bakker AD, Everts V, Klein-Nulend J. Mechanical loading prevents the stimulating effect of IL-1 $\beta$ on osteocyte-modulated osteoclastogenesis. Biochem Biophys Res Comm. (2012) 420:11-6. doi: 10.1016/j.bbrc.2012.02.099

78. Li JY, D’Amelio P, Robinson J, Walker LD, Vaccaro C, Luo T, et al. IL-17A is increased in humans with primary hyperparathyroidism and mediates PTH-induced bone loss in mice. Cell Metabol. (2015) 22:799-810.

79. Wu Q, Zhou X, Huang D, Yingchen JI, Kang F. IL-6 enhances osteocytemediated osteoclastogenesis by promoting JAK2 and RANKL activity in vitro. Cell Physiol Biochem. (2017) 41:1360-9. doi: 10.1159/000465455

80. Graves DT, Alshabab A, Albiero ML, Mattos M, Corrêa JD, Chen S, et al. Osteocytes play an important role in experimental periodontitis in healthy and diabetic mice through expression of RANKL. J Clin Periodontol. (2018) 45:285-92. doi: $10.1111 /$ jcpe.12851

81. Kim JH, Lee DE, Cha JH, Bak EJ, Yoo YJ. Receptor activator of nuclear factor- $\mathrm{\kappa} \mathrm{B}$ ligand and sclerostin expression in osteocytes of alveolar bone in 
rats with ligature-induced periodontitis. J Peridontol. (2014) 85:e370-378. doi: $10.1902 /$ jop. 2014.140230

82. Kim JH, Kim AR, Choi YH, Jang S, Woo GH, Cha JH, et al. Tumor necrosis factor- $\alpha$ antagonist diminishes osteocytic RANKL and sclerostin expression in diabetes rats with periodontitis. PloS ONE. (2017) 12:e0189702. doi: 10.1371/journal.pone.0189702

83. Heiland GR, Zwerina K, Baum W, Kireva T, Distler JH, Grisanti M, et al. Neutralisation of Dkk-1 protects from systemic bone loss during inflammation and reduces sclerostin expression. Ann Rheum Dis. (2010) 69:2152-9. doi: 10.1136/ard.2010.132852

84. Colditz J, Thiele S, Baschant U, Garbe AI, Niehrs C, Hofbauer LC, et al. Osteogenic Dkk1 mediates glucocorticoid-induced but not arthritis-induced bone loss. J Bone Miner Res. (2019) 2019:3702. doi: 10.1002/jbmr.3702

85. Shaw AT, Maeda Y, Gravallese EM. IL-17A deficiency promotes periosteal bone formation in a model of inflammatory arthritis. Arthr Res Ther. (2016) 18:104. doi: 10.1186/s13075-016-0998-x

86. Lin C, Jiang X, Dai Z, Guo X, Weng T, Wang J, et al. Sclerostin mediates bone response to mechanical unloading through antagonizing $\mathrm{Wnt} / \beta$-catenin signaling. J Bone Miner Res. (2009) 24:1651-61. doi: 10.1359/jbmr.090411

87. Baek K, Hwang HR, Park HJ, Kwon A, Qadir AS, Ko SH, et al. TNF$\alpha$ upregulates sclerostin expression in obese mice fed a high-fat diet. Cell Physiol. (2014) 229:640-50. doi: 10.1002/jcp.24487

88. David V, Martin A, Isakova T, Spaulding C, Qi L, Ramirez V, et al. Inflammation and functional iron deficiency regulate fibroblast growth factor 23 production. Kidney Int. (2016) 89:135-46. doi: 10.1038/ki.2015.290

89. Ito N, Wijenayaka AR, Prideaux M, Kogawa M, Ormsby RT, Evdokiou A, et al. Regulation of FGF23 expression in IDG-SW3 osteocytes and human bone by pro-inflammatory stimuli. Mol Cell Endocrinol. (2015) 399:208-18. doi: 10.1016/j.mce.2014.10.007

90. Uluçkan Ö, Jimenez M, Karbach S, Jeschke A, Gra-a O, Keller J, et al. Chronic skin inflammation leads to bone loss by IL-17-mediated inhibition of Wnt signaling in osteoblasts. Sci Transl Med. (2016) 8:330ra37. doi: 10.1126/scitranslmed.aad8996

91. Hemmatian H, Bakker AD, Klein-Nulend J, van Lenthe GH. Aging, osteocytes, and mechanotransduction. Curr Osteopor Rep. (2017) 15:401-11. doi: 10.1007/s11914-017-0402-z

92. Tiede-Lewis LM, Dallas SL. Changes in the osteocyte lacunocanalicular network with aging. Bone. (2019) 122:103-13. doi: 10.1016/j.bone.2019.01.025

93. Farr JN, Fraser DG, Wang H, Jaehn K, Ogrodnik MB, Weivoda MM, et al. Identification of senescent cells in the bone microenvironment. J Bone Miner Res. (2016) 31:1920-9. doi: 10.1002/jbmr.2892

94. Farr JN, Xu M, Weivoda MM, Monroe DG, Fraser DG, Onken JL, et al. Targeting cellular senescence prevents age-related bone loss in mice. Nature Med. (2017) 23:1072-82. doi: 10.1038/nm.4385
95. Sherk VD, Rosen CJ. Senescent and apoptotic osteocytes and aging: Exercise to the rescue? Bone. (2019) 121:255-8. doi: 10.1016/j.bone.2019.02.006

96. Cohen SB, Dore RK, Lane NE, Ory PA, Peterfy CG, Sharp JT, et al. Denosumab treatment effects on structural damage, bone mineral density, and bone turnover in rheumatoid arthritis. Arthritis Rheum. (2008) 58:1299309. doi: 10.1002/art.23417

97. Eddleston A, Marenzana M, Morre AR, Stephens P, Muzylak M, Marshall D. Robinson MK. A short treatment with an antibody to sclerostin can inhibit bone loss in an ongoing model of colitis. J Bone Miner Res. (2009) 24:1662-71. doi: 10.1359/jbmr.090403

98. Herrak P, Görtz B, Hayer S, Redlich K, Reiter E, Gasser J, et al. Zoledronic acid protects against local and systemic bone loss in tumor necrosis factor-mediated arthritis. Arthritis Rheum. (2004) 50:2327-37. doi: $10.1002 /$ art. 20384

99. Veerappan SG, O'Morain CA, Daly JS, Ryan BM. Review article: the effects of anti-tumour necrosis factor- $\alpha$ on bone metabolism in inflammatory bowel disease. Ailmentary Pharmcol Ther. (2011) 33:1261-72. doi: 10.1111/j.1365-2036.2011.04667.x

100. Atzeni F, Talotta R, Salaffi F, Cassinotti A, Varisco V, Battellino M, et al. Immunogenicity and autoimmunity during anti-TNF therapy. Autoimmunity Rev. (2013) 12:703-8. doi: 10.1016/j.autrev.2012. 10.021

101. Ding T, Deighton C. Complications of Anti-TNF therapies. Future Med. (2007) 2:587-97. doi: 10.2217/17460816.2.6.587

102. Metzger CE, Gong S, Aceves M, Bloomfield SA, Hook MA. Osteocytes reflect a pro-inflammatory state following spinal cord injury in a rodent model. Bone. (2019) 120:465-75. doi: 10.1016/j.bone.2018.12.007

103. El Kholy K, Van Dyke TE, Freire M, Chen T. Resolvin E1 promotes bone preservation under inflammatory conditions. Front Immunol. (2018) 9:1300. doi: $10.3389 /$ fimmu.2018.01300

104. Chan JK, Glass GE, Ersek A, Freidin A, Williams GA, Gowers K, et al. Lowdose TNF augments fracture healing in normal and osteoporotic bone by upregulating the innate immune response. EMBO Mol Med. (2015) 7:547-61. doi: 10.15252/emmm.201404487

Conflict of Interest Statement: The authors declare that the research was conducted in the absence of any commercial or financial relationships that could be construed as a potential conflict of interest.

Copyright ( $\odot 2019$ Metzger and Narayanan. This is an open-access article distributed under the terms of the Creative Commons Attribution License (CC BY). The use, distribution or reproduction in other forums is permitted, provided the original author(s) and the copyright owner(s) are credited and that the original publication in this journal is cited, in accordance with accepted academic practice. No use, distribution or reproduction is permitted which does not comply with these terms. 